\title{
Dignity, Autonomy, and Allocation of Scarce Medical Resources During COVID-19
}

\author{
David G. Kirchhoffer
}

Received: 7 May 2020 / Accepted: 17 July 2020

(C) Journal of Bioethical Inquiry Pty Ltd. 2020

\begin{abstract}
Ruth Macklin argued that dignity is nothing more than respect for persons or their autonomy. During the COVID-19 pandemic, difficult decisions are being made about the allocation of scarce resources. Respect for autonomy cannot justify rationing decisions. Justice can be invoked to justify rationing. However, this leaves an uncomfortable tension between the principles. Dignity is not a useless concept because it is able to account for why we respect autonomy and for why it can be legitimate to override autonomy in times of critical care resource shortages. Dignity affirms the worth of the human individual as a meaning-making embodied subject, who is always in relationship to others, the world, time, and transcendence, and who realizes their dignity through their moral behaviour. Such an understanding means people should be helped to make morally right decisions about their own treatment, which may include forgoing potentially beneficial treatment for the good of others. Respect for dignity does not require fulfilling the morally wrong choices of one who insists on treatment at the expense of others. Dignity also protects the discretion of clinicians to make decisions appropriate to their competence by prohibiting the application of broad-based criteria such as age.
\end{abstract}

Keywords Dignity · Autonomy · COVID-19 · Justice · Resource allocation $\cdot$ Resource rationing

D. Kirchhoffer $(\bowtie)$

Queensland Bioethics Centre, Australian Catholic University, 1100 Nudgee Road, Banyo, Queensland 4014, Australia e-mail: david.kirchhoffer@acu.edu.au

\section{Introduction}

Ruth Macklin (2003) argued that "dignity is a useless concept." For Macklin, dignity merely means respect for persons or their autonomy.

The COVID-19 pandemic has heightened the problem of scarce medical resource allocation. This is particularly so for the allocation of critical care resources, such as ventilators, for patients with acute respiratory distress syndrome (Rosenbaum 2020; Gibson, Qin, and Puah 2020). This has resulted in a proliferation of ethical guidelines attempting to address the problem of how to fairly allocate these resources (e.g. Emanuel et al. 2020; World Health Organization 2020). One thing is clear from these guidelines: respect for autonomy cannot alone do the ethical work to justify rationing. Indeed, it appears that concerns about autonomy may well be overridden in crisis moments.

I argue that dignity is not a useless concept. Rather, a proper conceptualization of human dignity can help guide ethical decision-making during COVID-19 and similar critical care crises. Instead of being reducible to respect for autonomy, dignity explains both why we care about autonomy and why it is appropriate to ration scarce medical resources even when this seems to be at odds with respect for autonomy.

I begin by demonstrating that concerns for both autonomy and justice can be grounded in concern for human dignity. I then describe a conceptualization of human dignity that adequately and properly takes into account the human being as an embodied, historicallysituated subject in relation to all that is, and describe 
how such a conceptualization can serve both a descriptive and a normative function in ethics. In light of this normative function of human dignity, I then explain how concerns for justice can limit autonomy whilst still respecting dignity. This is then applied to the problem of allocating scarce medical resources in times of pandemic like COVID-19. Finally, I argue that human dignity is particularly useful in that it also helps us address the moral distress for healthcare professionals of making rationing decisions.

\section{Autonomy and Justice Are Grounded in Dignity}

Respect for autonomy is an important principle in medical ethics. It protects us from overzealous researchers who would sacrifice us for the "greater good" and from overzealous doctors who want to apply disproportionate treatments. In the context of scarce resource allocation during COVID-19, the question is why, if a person wants a specific treatment that could help them, not giving them that treatment would be morally right. Respect for autonomy alone cannot explain the moral rightness of withholding treatment in this case. If anything, rationing during a pandemic seems to violate autonomy.

Beauchamp and Childress's (2019) principlism offers one solution. Justice balances the demands of autonomy, and respect for autonomy ensures that justice is not co-opted by the powerful at the expense of others. Consequently, it is not surprising that many of the guidelines point to the use of evidenced-based algorithms to assist clinical teams to ascertain who should get the scarce resources based on an estimation of the proportional benefit of treatment or the disproportionate burden. Yet, this still leaves a dissatisfying tension between the principles.

A more satisfying solution explains both why we respect autonomy when possible and why justice can override autonomy in certain circumstances. This can be done by recognizing that these principles are meaningful precisely because they serve an overarching valuehuman dignity. Justice is about human individuals getting their due; autonomy is about human individuals being able to realize morally meaningful choices in their lives. Neither the due given nor the choice made are primary, because without human individuals as the objects of justice and autonomy, the principles are meaningless.
Having established that justice and autonomy presume a prior concern for human individuals, the next section elaborates a conceptualization of human dignity that takes the human individual adequately into account.

\section{Human Dignity: Both Inherent and Acquired, Descriptive and Normative}

Dignity means worth, that is, value beyond price. $\mathrm{Hu}-$ man dignity affirms the worth of both our ontological and existential realities. Dignity is both something we always already have (inherent dignity) and something that can be acquired or lost (acquired dignity).

Ontologically, I possess an original and unchanging biological identity and am born into an original set of relationships to the world, to others, to social institutions, to time and history, and to transcendent values (Janssens 1980; Kirchhoffer 2019). I am always some mother's child (Kittay 2005). I essentially possess a specifically human set of capacities that includes not only reason and free choice (autonomy) but also the capacity to feel and express emotions, to take responsibility, to play, to create, to care, to receive care, and so on (e.g., Nussbaum 2000). My humanity is neither reducible to a single capacity, such as autonomy, nor determined by the actualization of any of these capacities. Inherent dignity affirms the worth of the essential potential that inheres in each human individual, constituted by a unique biological identity in given relationships and possessing a characteristically human set of capacities.

Existentially, the potential that inheres in my being human is realized as a sense of pride or self-worth (acquired dignity). We think of those people who live morally good lives as dignified. So, to acquire dignity as self-worth, I engage my inherent potential in morally good behaviour, that is, reasoning, judgements, choices, and actions in relationships.

The desire for dignity arises from my experience of the ambiguity of relationships. Some relationships affirm my self-worth, for example, loving support. Others threaten my self-worth, for example, the threat of a deadly coronavirus pandemic that does not care who I am and that may not be treated if I am infected because some "algorithm" says "no." Such experiences provoke a desire to think and act in ways that affirm my sense of self-worth. It is a matter of existential survival (Gilligan 1997). 
Recognizing how these ontological and existential components of what we mean by the human individual give rise to a concern for the worth of both what I am and who I am becoming means that dignity can serve both a descriptive and a normative function in ethics. That is, it can help to explain both why I subjectively choose to engage in certain kinds of moral behaviour and how I objectively ought to act morally.

Dignity is descriptive because it can help us to understand why people do things. What one considers to be self-worth-acquiring behaviour will depend on what one subjectively believes constitutes dignity as selfworth. If I believe that dignity is protected by punishment of those who are disrespectful, then threats to my sense of self-worth will likely be met with violence. By contrast, if I believe the dignified person acts selflessly, I will realize my self-worth by working for the good of others.

Dignity is also normative. One's understanding of dignity as self-worth and moral behaviour can be evaluated as objectively morally bad or morally wrong respectively. To be objectively morally good, my sense of self-worth cannot rely on beliefs or actions that dehumanize or demonize others, that is, deny their dignity. To be objectively morally good and right, my beliefs and actions must promote or at least not violate the inherent dignity or objectively morally legitimate acquired self-worth of others. To do so would undermine my own claims of dignity. I cannot expect others to respect my dignity if I will not respect others' dignity.

The next section shows how this normative understanding of human dignity enables us to explain why it is morally legitimate for concerns for justice to override individual autonomy even if the individual in question subjectively believes he or she is morally right. At the same time, that individual never loses inherent dignity.

\section{Dignity, Autonomy, and Justice}

Respect for autonomy is grounded in dignity because autonomy is one of the essential capacities we use to realize our self-worth. We protect both the capacity to think about and make meaningful choices and the choices made in the service of realizing an objectively morally legitimate self-worth. Though we must protect the capacity to reason and make choices, we are not obliged to protect morally illegitimate reasoning, choices, and behaviours.
When an individual's subjective understanding of dignity as self-worth is objectively mistaken - that is, their self-worth relies on beliefs or behaviours that violate the dignity of others - then justice allows their freedom to be limited in order to protect them and others. Justice also obliges us, out of respect for their inherent dignity (which they never lose), to work to help them to realize their acquired dignity through an objectively morally good conception of dignity as self-worth and morally right behaviours.

The next section applies this conceptualization of human dignity as both descriptive and normative to the problem of acute care resource allocation during COVID-19.

\section{Dignity and Scarce Medical Resources}

Morally acceptable scarce resource allocation should not undermine:

A. inherent dignity as potential to live a morallymeaningful life, or

B. acquired dignity as a morally good sense of selfworth (i.e., one that does not rely on diminishing A or B in others), or

C. the moral rightness of one's own behaviours (you can't ask someone to do something that they believe is morally wrong because it violates A or B in others)

This applies not only to patients, but also to the clinicians, health workers, and administrators. Their dignity is also at stake.

In what follows, I discuss how taking dignity seriously during COVID-19 means that:

- autonomy should still be respected by obtaining informed consent where possible, including advance care planning;

- as in normal end-of-life decision-making, an individual could come to a morally right decision to forgo medically futile treatment;

- in times of resource scarcity, distributive justice requires that the dignity of concrete (not hypothetical) others be included in moral consideration of withholding and withdrawing treatment, with the help of adequate information from clinical advisors; 
- where a person lacks capacity, decisions to forgo treatment can be made in light of the above considerations based on what a person ought to do;

- where a person insists on medically-futile treatment, this demand need not be followed as there is no obligation to participate in objectively morally wrong behaviour (C), that is, behaviour that objectively undermines the dignity of others (A and $\mathrm{B}$ ).

\section{Respect Autonomy by Obtaining Informed Consent} and Advance Care Planning

COVID-19 threatens the goods of life and health, which we need to pursue our dignity as self-worth, and it threatens our self-worth because we feel vulnerable and mortal. Seeking help from others when we are ill is part of how we protect and restore our dignity (both inherent and acquired).

Because autonomy is one of the inherent human capacities we use to realize our dignity as self-worth, autonomy must in principle be respected in clinical situations where it is present, for example, the requirement for a competent individual to consent to treatment and their right to refuse treatment. Adequately informing an individual respects autonomy because accurate knowledge informs moral reasoning, judgements, and choices. Informed consent procedures support people in reaching objectively morally good decisions that help them to restore their dignity as self-worth.

When critical care resources are scarce, this in no way diminishes the obligation to respect autonomy through adequately informing a person and where possible obtaining consent. If a person cannot be given a potentially beneficial treatment because of scarce resources, not making the effort to adequately inform a person and obtain consent (or at least agreement) would be a violation of their dignity.

Such omissions also damage the acquired dignity of clinical staff because they are engaging in beliefs or behaviours that undermine the dignity of their patients.

Similarly, respect for autonomy requires that advance care planning conversations, including appropriate discussions about when it would be proportionate to withhold or withdraw treatment for the particular individual in question, should be held as soon as practicable.
No One is Morally Obliged to Pursue Medically Futile Treatment

It is during such conversations that one might come to the decision that the morally right thing to do is to forgo further treatment. Life and health, though fundamental to the pursuit of dignity, are not absolute goods (Boyle 2002). There is no obligation to pursue them at all costs. Regardless of resource scarcity, the first questions are the appropriate clinical questions of proportionate therapeutic benefit or disproportionate burden in the circumstances. Whilst one can partly rely on evidence-based algorithms and even machine learning to aid this evaluation, to take dignity seriously means taking seriously everything about an individual: physical health, relationships, achievements, hopes and desires, and especially how they feel they have realized a sense of selfworth. This means that human judgement is essential to the process. Based on adequate information and cognizant of the moral meaning of my actions, the morally right conception of self-worth might lead me to the recognition that the morally appropriate thing for me to do is to not start or to end a treatment that has no proportionate benefit or is overly burdensome.

\section{Take Relative Benefit to Concrete Others into Account}

Where resources are limited, the moral rightness of withholding or withdrawing treatment must now include consideration of my circumstances relative to those of others whose dignity is also threatened by illness. Relative medical futility must be considered.

If a limited clinical resource is more likely to benefit particular others, then it would be morally acceptable for me to decide to forgo treatment that might have been beneficial to me. To reach this decision in a way that adequately respects my dignity requires adequate information and also that those who are advising me (the clinical teams) are adequately informed about the circumstances of concrete others.

If the resources become available again, then my initial decision should be revisited, since this was never about an absolute futility in my case in the first place.

Decide for Those Who Lack Autonomy Based on What They Ought to Do

Resource allocation decisions may affect patients who are incompetent at the time, for example, sedated on a 
ventilator. Dignity is first respected by efforts to have appropriate care-planning discussions about when and what treatment might be withheld or withdrawn. Circumstances may change, however, or unexpected patients may end up incapacitated. In such cases, realization of dignity as self-worth through morally right behaviour by the substitute decision-makers and clinical teams is important. Because autonomy is absent, substitute decision-makers and the clinical team need to choose on behalf of the incapacitated person. They must choose what they agree the individual ought to want to do in the given circumstances (McCormick 1974). All of the aforementioned considerations need to be taken into account. By making a vicarious morally right decision, the decision-makers support the ultimate realization of the dignity of the other person by making morally meaningful choices that serve the dignity of all.

Autonomy Can Be Limited When an Individual Is Objectively Morally Wrong

Despite best efforts to promote dignity through informed decision-making, an individual may still insist that they should be treated regardless of others. Grounding autonomy in dignity means that choices can be morally evaluated according to the normative function of dignity. Where a choice violates inherent dignity (A) or morally legitimate acquired dignity of another (B), appropriate decision-makers can enforce measures for the protection of the dignity of all. There is no obligation to fulfil morally wrong demands (C). To do so would make the clinical team morally complicit, and they would thereby undermine their own realization of dignity as self-worth. It would also increase rather than alleviate moral distress for decision-makers and clinical teams.

\section{Dignity, Responsibility, and Humility}

Grounding resource allocation decisions in respect for dignity means taking individual human meaningmaking seriously. This helps us to avoid cold, calculating proceduralism or decisions based on broad criteria, such as age. Such approaches violate the inherent dignity of human beings as well as their legitimate acquired dignity as self-worth. They also violate the dignity of clinical care teams, who are the people best situated to assist decision-making for particular individuals. Broad- based criteria violate the discretion of clinicians to make decisions appropriate to their clinical competence (Zussman 1992) and hence violate their acquired sense of self-worth as professionals. This can lead to an increased burden of moral distress (Williamson, Murphy, and Greenberg 2020).

Finally, we realize our dignity in concrete historical circumstances. Every human individual exists in a specific place and time and is consequently limited by what is possible and likely to be known with any certainty. Since knowledge is an important foundation of decision-making and since becoming a virtuous person is a matter of practical application of knowledge through moral reasoning, judgement, choices, and actions over time, it is self-evident that, even with the best intentions, we might still get moral decisions wrong. In the rapidly changing knowledge-landscape and situational status of novel pandemics like COVID-19, recognizing these limitations is essential if we are also going to be able to act with sincerity and a clear moral conscience. An individual who sincerely pursues the realization of their dignity through the promotion of the dignity of all others cannot lose their dignity through unintentional error. Consequently, healthcare organizations should provide adequate pastoral support for decision-makers, and difficult decisions are best made by multidisciplinary teams, both because this increases the likelihood that the best available knowledge is taken into account and because it shares the burden of having to make decisions in circumstances where one cannot be absolutely certain that one is right.

In the end, we want to be able to hold our heads up high and say that we preserved our dignity as self-worth by sincerely working for the dignity of all, humbly recognizing that sometimes, despite our best intentions, we might have got it wrong.

\section{References}

Beauchamp, T.L., and J.F. Childress. 2019. Principles of biomedical ethics, 8th ed. New York: Oxford University Press.

Boyle, J. 2002. Limiting access to healthcare: A traditional Roman Catholic analysis. In Allocating scarce medical resources: Roman Catholic perpectives, edited by H.T. Engelhardt, Jr., and M.J. Cherry, 77-95. Washington, D.C.: Georgetown University Press.

Emanuel, E.J., G. Persad, R. Upshur, et al. 2020. Fair allocation of scarce medical resources in the time of covid-19. New England Journal of Medicine, published online at nejm.org, March 23. https://doi.org/10.1056/NEJMsb2005114 
Gibson, P.G., L. Qin, and S. Puah. 2020. COVID-19 ARDS: Clinical features and differences to "usual" pre-COVID ARDS. Medical Journal of Australia. Preprint, April 24. https:/www.mja.com.au/journal/2020/covid-19-ardsclinical-features-and-differences-usual-pre-covid-ards.

Gilligan, J. 1997. Violence: Reflections on a national epidemic. New York: Vintage Books.

Janssens, L. 1980. Artificial insemination: Ethical considerations. Louvain Studies 8(1): 3-29.

Kirchhoffer, D.G. 2019. Dignity, being and becoming in research ethics. In Beyond autonomy: Limits and alternatives to informed consent in research ethics and law, edited by D.G. Kirchhoffer and B.J. Richards, 117-132. Cambridge: Cambridge University Press.

Kittay, E.F. 2005. Equality, dignity, and disability. In Perspectives on equality: The second Seamus Heaney lectures, edited by M.A. Lyons and F. Waldron, 93-119. Dublin: The Liffey Press.

Macklin, R. 2003. Dignity is a useless concept. BMJ 327(7429): 1419-1420. https://doi.org/10.1136/bmj.327.7429.1419.

McCormick, R.A. 1974. Proxy consent in the experimentation situation. Perspectives in Biology and Medicine 18(1): 220. https://doi.org/10.1353/pbm.1974.0001.
Nussbaum, M. 2000. Women and human development: The capabilities approach. Cambridge: Cambridge University Press.

Rosenbaum, L. 2020. Facing Covid-19 in Italy-Ethics, logistics, and therapeutics on the epidemic's front line. New England Journal of Medicine 382(20): 1873-1875. https://doi. org/10.1056/NEJMp2005492

Williamson, V., D. Murphy, and N. Greenberg. 2020. COVID-19 and experiences of moral injury in front-line key workers. Occupational Medicine kqaa052. https://doi.org/10.1093 /occmed/kqaa052

World Health Organization. 2020. Resources on ethics and COVID-19. https://www.who.int/ethics/topics/outbreaksemergencies/covid-19/en/. Accessed May 19, 2020.

Zussman, R. 1992. Intensive care: Medical ethics and the medical profession. Chicago: University of Chicago Press.

Publisher's note Springer Nature remains neutral with regard to jurisdictional claims in published maps and institutional affiliations. 